Research Article

\title{
Composite Hydrogel of Poly(acrylamide) and Starch as Potential System for Controlled Release of Amoxicillin and Inhibition of Bacterial Growth
}

\author{
Ana V. Torres-Figueroa $\left(\mathbb{D},{ }^{1}\right.$ Cinthia J. Pérez-Martínez $\left(\mathbb{D},{ }^{1}\right.$ Teresa del Castillo-Castro $\mathbb{D}^{\mathrm{D}}{ }^{2}$ \\ Enrique Bolado-Martínez $\mathbb{D}^{1},{ }^{1}$ María A. G. Corella-Madueño $\mathbb{D},^{1}$ \\ Alejandro M. García-Alegría $\mathbb{D}^{1},{ }^{1}$ Tania E. Lara-Ceniceros $\mathbb{D}^{3}{ }^{3}$ \\ and Lorena Armenta-Villegas $\mathbb{D}^{1}$ \\ ${ }^{1}$ Departamento de Ciencias Químico Biológicas, Universidad de Sonora, CP 83000, Hermosillo, Sonora, Mexico \\ ${ }^{2}$ Departamento de Investigación en Polímeros y Materiales, Universidad de Sonora, CP 83000, Hermosillo, Sonora, Mexico \\ ${ }^{3}$ Advanced Functional Materials and Nanotechnology Group, \\ Centro de Investigación en Materiales Avanzados S. C. (CIMAV-Unidad Monterrey), CP 66628, Apodaca, Nuevo León, Mexico
}

Correspondence should be addressed to Cinthia J. Pérez-Martínez; jhovanna.perez@unison.mx

Received 7 July 2020; Revised 18 October 2020; Accepted 27 October 2020; Published 16 November 2020

Academic Editor: Gabriel Navarrete-Vazquez

Copyright ( $) 2020$ Ana V. Torres-Figueroa et al. This is an open access article distributed under the Creative Commons Attribution License, which permits unrestricted use, distribution, and reproduction in any medium, provided the original work is properly cited.

\begin{abstract}
Novel composite hydrogels of poly(acrylamide) (PAAm) and starch, at different ratios, were studied as potential platforms for controlled release of amoxicillin. The composite hydrogels were characterized by Fourier transform infrared spectroscopy (FTIR), scanning electron microscopy (SEM), energy-dispersive X-ray spectroscopy (EDX), and swelling kinetic measurements. The morphology analysis revealed the presence of starch granules well embedded within the PAAm network. The increase in starch content increased the rate of water uptake and the swelling degree at equilibrium. The amoxicillin release kinetics was sensitive to $\mathrm{pH}$ and temperature conditions. The in vitro bacterial growth inhibition of antibiotic-loaded hydrogels was tested though disc diffusion assays with Escherichia coli ATCC 25922, Staphylococcus aureus ATCC 25923, and a carbapenemase producer Pseudomonas aeruginosa strain. The optimal release profile at physiological conditions and the powerful bacteria growth inhibition effects of amoxicillin-loaded hydrogels evidenced its potential for biomedical applications, particularly in oral administration and the local treatment of bacterial infections.
\end{abstract}

\section{Introduction}

Materials capable of responding to multiple external stimuli, such as temperature [1], $\mathrm{pH}[2]$, ionic strength [3], electrical potentials [4], and biochemical activity [5], have received growing interest in recent years to be used in biomedical applications [6-8]. Particularly, polymeric hydrogels are well recognized within the field of stimulus-sensitive materials. These three-dimensional hydrophilic polymer networks, held together either by chemical or physical interactions $[9,10]$, absorb large amounts of aqueous fluids [11] coupled with a high permeability to small molecules and a soft consistency, which makes them similar to living tissues [12]. Their applications encompass wound dressing uses [11], tissue engineering [13], and controlled drug delivery of a wide range of bioactive compounds [14], including antiviral drugs [10], contraceptives [12], and anticoagulants [15], among others.

PAAm hydrogels have been widely studied, owing to their excellent swelling capabilities [16], thermal stability [17], nontoxic properties [18], biological inertness [11], and biocompatibility, which can be improved by their combination with other biomaterials [19]. In general, the properties of polymer mixtures depend on the interactions that 
occur between their components. Some fillers also provide highly reactive functional groups, such as carboxyl groups, hydroxyl groups, and aromatic rings, for further chemical modifications, that can be tailored to obtain the desired properties [20, 21].

In this concern, PAAm-based composite hydrogels have been prepared to promote the versatility of precursor polymers and to achieve multifunctional capabilities in final materials. Suitable combinations of PAAm with chitosan [11], polyaniline [22], poly(acrylic acid) [23], proteins [24], or polysaccharides $[25,26]$ have shown outstanding mechanical and therapeutic performance, along with an enhanced biocompatibility $[27,28]$.

Moreover, the incorporation of biopolymers to PAAm hydrogels can modify the porous structure of the hydrogel, providing a suitable environment for cell growth and improving their biocompatibility. Kavousi and Nikfarjam [29] found that starch nanoparticles cross-linked with citric acid change the macroporous structure of PAAm-based hydrogels, producing a highly porous and interconnected structure. The cell adhesion and cell viability studies of materials evidenced an improved biocompatibility and a suitable environment for cell growth.

Polysaccharides are strong candidates for developing biomaterials due, among other qualities, to their biocompatibility [30]. Drug delivery systems based on polysaccharides have shown an excellent response for the treatment of respiratory diseases [31] and glaucoma [32], as well as for the supply of antipsychotic [31], antipyretic, and analgesic drugs with anti-inflammatory activity [33].

The starch, after cellulose, is the second most abundant polysaccharide. This biopolymer is recognized by its low cost, biodegradability, biocompatibility, and inherent bioactivity [27, 34]. Several studies have shown the potential of starch-based materials for the controlled release of bioactive molecules. Dafe et al. [35] reported the efficient use of pectin/starch hydrogels as a probiotic carrier for oral delivery. In a different approach, Perez et al. [36] carried out the synthesis of chitosan/starch hydrogels as a potential delivery system for plant growth-promoting bacteria. Sethi et al. [33] prepared a hydrogel of karaya gum/starch as a suitable oral carrier of paracetamol and aspirin.

Few research studies have dealt with the combination of PAAm and starch to design composite hydrogels. Previous reports have mostly involved grafting reactions to obtain copolymers that subsequently were used for producing multicomponent networks [27, 37-39]. The hydrogels have been mainly evaluated in dyes adsorption [40], as disinfectants [41], and for the controlled release of fertilizers [42] and fungicides [43].

Despite the promising advantages of the use of PAAm and starch in the biomedical area, studies focused on the suitable combination of both polymers for controlled release of drugs are scarce. In this concern, Murthy et al. [38] prepared semiinterpenetrating polymer networks of starch and a random copolymer of poly(acrylamide-co-sodium methacrylate) to evaluate the swelling and diffusion properties of materials in simulated biological fluids. The authors found a promising performance of biomaterials for pharmaceutical applications.
The aim of the present work is to study the effectiveness of composite hydrogels of PAAm/starch for the controlled release of amoxicillin, a broad-spectrum drug and first choice for the treatment of various infections. Amoxicillin can be used as prophylaxis against bacterial endocarditis in patients with prosthetic joint replacements and dentistry [44]. Composite hydrogels were characterized by FTIR, swelling kinetic measurements, SEM, and EDX. Amoxicillin-release profiles were obtained in vitro under physiological conditions of $\mathrm{pH}$ and temperature. Furthermore, the antibacterial activity against Escherichia coli ATCC 25922, Staphylococcus aureus ATCC 25923, and a carbapenemase producer Pseudomonas aeruginosa strain was evaluated. The microbiological studies demonstrated inhibition zones for amoxicillin-loaded PAAm/starch hydrogels equal and even greater than those expected for the commercial dicks.

\section{Materials and Methods}

2.1. Materials. The PAAm/starch and amoxicillin (as amoxicillin sodium) hydrogels were prepared using acrylamide (AAm, 99\%; Sigma-Aldrich), methylene-bis(acrylamide) (MBAAm, 99\%; Sigma-Aldrich), $N, N, N^{\prime}, N^{\prime}$ tetramethyl-ethylenediamine (TEMED, 99\%; Sigma-Aldrich), amoxicillin (potency: $\geq 900 \mu \mathrm{g}$ per mg; Sigma-Aldrich), sodium phosphate monobasic (99\%; Sigma-Aldrich), disodium hydrogen phosphate (99\%; Sigma-Aldrich), citric acid (99.5\%; Sigma-Aldrich), ammonium persulfate (APS, 98.7\%; J. T. Bayer), starch from potato (98\%; Monterrey Chemical Products), and sodium hydroxide (97\%; Meyer). The Mueller-Hinton agar culture media (BD Becton Dickinson), Mueller-Hinton broth (BD Becton Dickinson), and trypticase soy agar (BD Becton Dickinson) were used to test the controlled release of amoxicillin held within the PAAm/starch hydrogels in Escherichia coli strain ATCC 25922, Staphylococcus aureus strain ATCC 25923, and Pseudomonas aeruginosa (a carbapenemase producer and resistant to amikacin strain).

2.2. Preparation of PAAm/Starch Hydrogels. The hydrogels of PAAm/starch were obtained upon addition of acrylamide solution (29 g AAm monomer and $1 \mathrm{~g}$ of MBAAm crosslinker in $100 \mathrm{~mL}$ of aqueous solution) into a starch solution (15 wt\%) using an ice-chilled $3.6 \mathrm{~cm}$ (internal diameter) cylindrical mold. Gelation process was initiated by adding $0.5 \mathrm{~mL}$ of APS solution and $25 \mu \mathrm{L}$ of TEMED reactant (accelerator). Hydrogel composites were prepared in PAAm/starch volumetric ratios of 100/0, 90/10, 80/20, 70/ $30,60 / 40$, and 50/50. The hydrogels were washed with deionized water several times for $48 \mathrm{~h}$ and further freezedried during $48 \mathrm{~h}$ in a Labconco FreeZone 4.5 unit under a vacuum atmosphere of $0.5 \mathrm{mBar}$ and $-46^{\circ} \mathrm{C}$ in the collector. Figure 1 illustrates the preparation of PAAm/starch composite hydrogels.

2.3. Characterization Techniques. FTIR spectra of dried hydrogel were recorded in a PerkinElmer Spectrum GX spectrometer (USA) by the $\mathrm{KBr}$ pellet technique in the range 


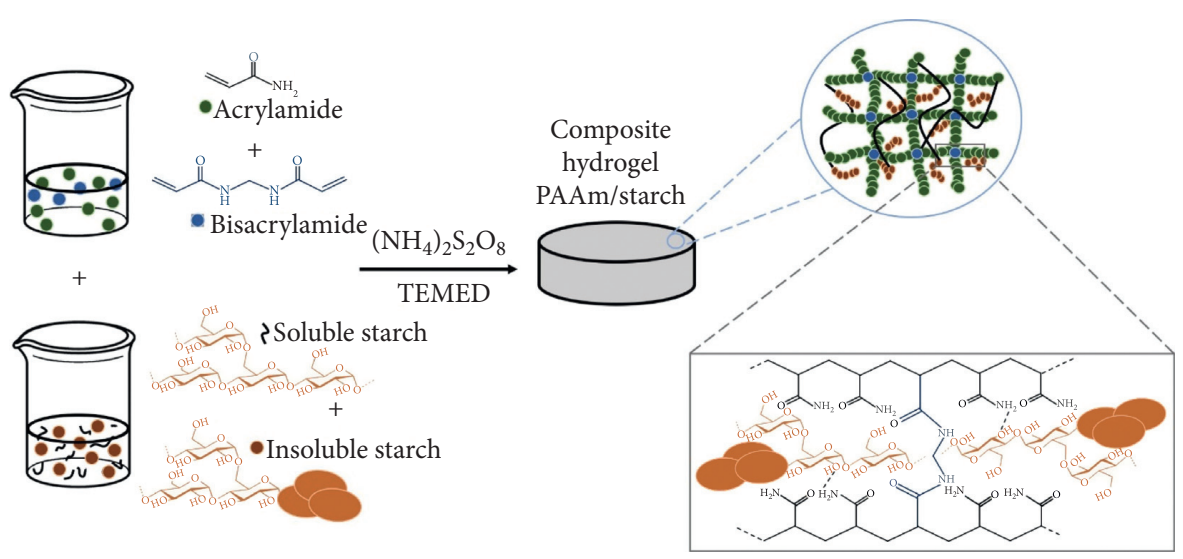

Figure 1: PAAm/starch composite hydrogel preparation method.

of $4000-400 \mathrm{~cm}^{-1}$. The morphology and the elemental composition of hydrogels were analyzed by SEM using JEOL 6010 Plus and ESEM JEOL 7610F scanning electron microscopes. The samples were analyzed in dry and swollen states. For the analysis of dry samples, ultrathin sections of hydrogels were cut at $-150^{\circ} \mathrm{C}$ with a cryoultramicrotome RMC products and placed on copper grids. The samples were allowed to dry at room temperature for the analysis. To examine the morphology of the hydrated samples, sections of xerogels were cut at room temperature and then immersed in DI water for $6 \mathrm{~h}$ before the analysis. Measurements were made in environmental mode.

The swelling properties of hydrogels were tested through the gravimetric method. Cylindrical shape xerogel samples $(3.6 \mathrm{~cm}$ diameter and a thickness of $0.7 \mathrm{~cm}$ ) of known weight $\left(w_{0}\right)$ were immersed in $250 \mathrm{~mL}$ of sodium phosphate buffer (PBS, pH 7.4, 0.1 M) at room temperature. The samples were removed from the swelling medium at specific times $(t)$, blotted, weighed $\left(w_{t}\right)$, and placed in the same water bath until a constant weight was reached. The swelling percent $(S$ $\%)$ at time $t$ was calculated from the following equation:

$$
S \%=\frac{w_{t}-w_{0}}{w_{0}} \times 100
$$

All swelling experiments were performed in triplicate for each $\mathrm{PAAm} / \mathrm{starch}$ ratio.

2.4. Hydrogel Loading with Amoxicillin. The loading of amoxicillin in the hydrogels was carried out by the swelling equilibrium method. Xerogel samples of PAAm/starch hydrogels were loaded by sorption in $5 \mathrm{~mL}$ of aqueous amoxicillin solution $\left(0.2 \mathrm{~g} \mathrm{~mL}^{-1}\right)$ for $48 \mathrm{~h}$ and freeze-dried. Loading content was determined from the difference between the initial and final amounts of the drug in the loading solution. The amount of released amoxicillin was quantified by recording the absorbance at $273 \mathrm{~nm}$ in a PerkinElmer Lambda $20 \mathrm{UV}$-Vis spectrophotometer and the subsequent interpolation of the value in a calibration curve. The calibration curve was obtained by preparing of standard solutions containing from 0.2 to $1.2 \mathrm{mM}$ of amoxicillin and measuring the corresponding absorbance in the UV-Vis unit at $273 \mathrm{~nm}$ (Figure 2).

The drug loading efficiency of hydrogels was determined by the following equation [45]:

$$
\text { loading efficiency }=\frac{\text { total amount of amoxicillin }- \text { free amoxicillin }}{\text { total amount of amoxicillin }} \times 100
$$

2.5. Controlled Release of Amoxicillin. The experiments of drug release were performed in a phosphate-buffered saline solution (PBS, 0.1 M, pH 7.4) and phosphate-citric acid buffered solution (PCA, 0.1 M, pH 3.0). The amoxicillinloaded hydrogels were immersed in $250 \mathrm{~mL}$ of buffer solutions at controlled temperatures of 25 or $37^{\circ} \mathrm{C}$, using an incubator (Barnstead Lab-Line MaxQ 4000) with continuous orbital stirring of $80 \mathrm{rpm}$. Aliquots of $100 \mu \mathrm{L}$ were withdrawn at specific time intervals. The concentration of amoxicillin was determined by recording the absorbance at $273 \mathrm{~nm}$ in a PerkinElmer Lambda $20 \mathrm{UV}-\mathrm{V}$ is spectrophotometer and the subsequent interpolation of the value in the calibration curve (Figure 2).

2.6. Mechanism and Mathematical Modeling for Amoxicillin Release from PAAm/Starch Hydrogels. Data obtained in the in vitro amoxicillin release studies were fitted to the Korsmeyer-Peppas model [46] (equation 3) to evaluate the release mechanism of the drug from the composite hydrogels:

$$
\frac{M t}{M_{\infty}}=k t^{n}
$$




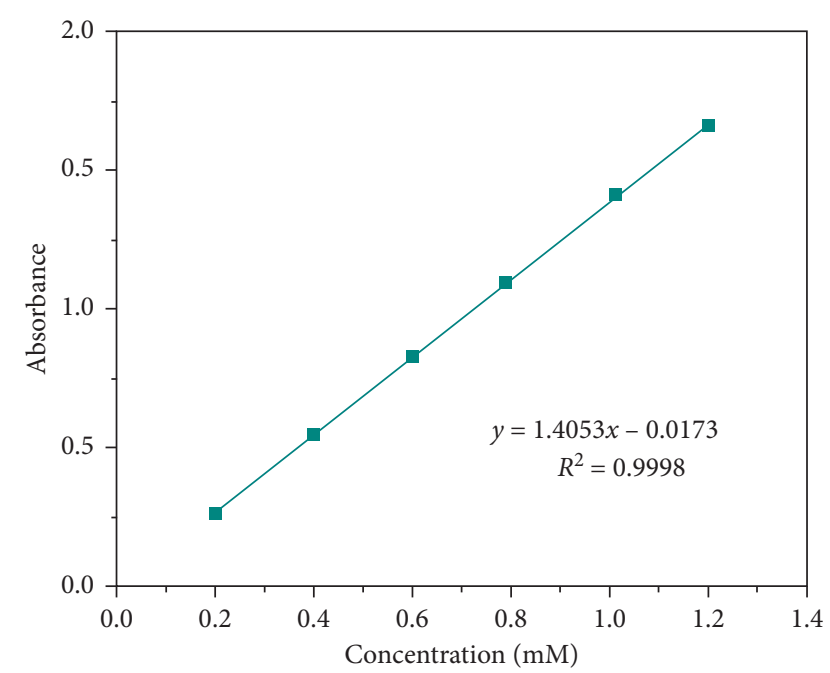

FIgURE 2: Calibration curve of amoxicillin obtained by UV-Vis absorbance at $273 \mathrm{~nm}$.

Here, $M_{t}$ and $M_{\infty}$ are the hydrogel weights at time $t$ and equilibrium, respectively; $k$ is the release rate coefficient, and $n$ is the diffusion exponent that can be related to the drug transport mechanism.

2.7. Bacterial Growth Inhibition Assay. To obtain hydrogels with dimensions comparable to those of commercial discs ( $6 \mathrm{~mm}$ diameter, $1 \mathrm{~mm}$ thick), $80 \mu \mathrm{L}$ of the polymer precursor solution was dropped into molds. The precursor polymer solution was prepared by dissolving $29 \mathrm{~g}$ AAm monomer and $1 \mathrm{~g}$ of MBAAm crosslinker in $100 \mathrm{~mL}$ of aqueous solution into a starch solution $(15 \mathrm{wt} \%)$. The resulting hydrogels were lyophilized in a LABCONCO, FreeZone 4.5 equipment for $48 \mathrm{~h}$ under a vacuum atmosphere of $0.5 \mathrm{mBar}$ and $-46^{\circ} \mathrm{C}$ in the collector. The PAAm/starch hydrogel discs were loaded with 600 and $1200 \mu \mathrm{g}$ of amoxicillin. The amoxicillin-free PAAm/ starch hydrogel served as a negative control.

The effect of released amoxicillin from hydrogels was evaluated in three bacterial isolates: Escherichia coli ATCC 25922, Staphylococcus aureus ATCC 25923, and a carbapenemase producer, and resistant to amikacin, Pseudomonas aeruginosa strain by disc diffusion assay. In brief, bacterial strains were growth in Mueller-Hinton broth and then swabbed in Mueller-Hinton agar plates. The hydrogels loaded with the antibiotic were placed on the surface of the inoculated agar and commercial discs of amoxicillin/clavulanic acid (20/ $10 \mu \mathrm{g})$, amikacin $(30 \mu \mathrm{g})$, and imipenem $(10 \mu \mathrm{g})$ and then incubated at $37^{\circ} \mathrm{C}$. After 24 hours of incubation, the inhibition zone was obtained by the release of the drug from the hydrogels, and the commercial discs were read (modified from Zhu et al. [47]). Each experiment was run by triplicate.

2.8. Statistical Analyses. The data were presented as mean \pm standard deviation. For comparative studies, the data were analyzed by analysis of variance (ANOVA) with an acceptable significance level of $P<0.05$ using the statistical package NCSS 2007.

\section{Results and Discussion}

Hydrogel composite networks were successfully prepared by the free radical polymerization of acrylamide by using APS/ TEMED initiating system in the presence of starch-containing solutions. The initiator acts by attacking the double bonds of acrylamide and bisacrylamide to give rise to the formation of the PAAm network in the presence of starch. The schematic hydrogel network formation is depicted in Figure 1. The hydrogels displayed a uniform appearance, with a translucent coloration that became opaque with the increase in the starch content, as shown in Figure 3.

3.1. FTIR Analysis. Figure 4 shows the FTIR spectra of the starch, the PAAm hydrogel, and that of representative PAAm/starch composite hydrogel (50/50). The spectrum of PAAm hydrogel shows a broad band located from 3500 to $3100 \mathrm{~cm}^{-1}$, which was attributed to the N-H vibrations [48] and a smaller peak at $2941 \mathrm{~cm}^{-1}$, corresponding to the $\mathrm{C}-\mathrm{H}$ stretching vibrations of the methylene group [49]. The bands at $1667 \mathrm{~cm}^{-1}$ can be assigned to $\mathrm{C}=\mathrm{O}$ moiety of the $-\mathrm{CO}$ $\mathrm{NH}_{2}$ group (amide-I) [49, 50]. Furthermore, the absorption band at $1466 \mathrm{~cm}^{-1}$ was related to the vibrations of $\mathrm{C}-\mathrm{N}$ bond [51].

The spectrum of starch shows the typical absorptions of the polysaccharide. The broad band located at $3383 \mathrm{~cm}^{-1}$ is due to the stretching vibration of $-\mathrm{OH}$ [52]. The band associated with the $\mathrm{C}-\mathrm{H}$ stretching vibration appears at $2933 \mathrm{~cm}^{-1}$ [53]. The absorption bands at 1650, 1460, and $1374 \mathrm{~cm}^{-1}$ are related to $\mathrm{C}-\mathrm{OH}$ bending, and those at 1163 , 1081 , and $984 \mathrm{~cm}^{-1}$ are assigned to C-O stretching vibrations [48].

The incorporation of starch into the PAAm hydrogels produced spectral changes in its base spectrum. A more defined contribution is observed in the broad band between 3600 and $3200 \mathrm{~cm}^{-1}$, which can be attributed to the superposition of the $\mathrm{O}-\mathrm{H}$ stretch band of starch and the $\mathrm{N}-\mathrm{H}$ stretch band of the acrylamide moiety [49]. The signal at $2930 \mathrm{~cm}^{-1}$ is assigned to the C-H stretching vibrations of the methylene group; meanwhile, those at 1099 and $988 \mathrm{~cm}^{-1}$ are attributed to the $\mathrm{C}-\mathrm{O}-\mathrm{C}$ stretching vibrations. It should be noticed that the band at $1466 \mathrm{~cm}^{-1}$ corresponding to $\mathrm{NH}_{2}$ bending vibration of PAAm appears at a shorter wavenumber $\left(1456 \mathrm{~cm}^{-1}\right)$ in the PAAm/starch spectrum, which suggests some physical interactions between both components, e.g., hydrogen bonds [48].

The amoxicillin-loading in hydrogels was also analyzed by FTIR. Figure 5 shows the FTIR spectrum of pure drug and those of drug-free and drug-containing hydrogels PAAm/ starch $100 / 0$ and 50/50. The spectrum of amoxicillin shows the typical absorptions of the antibiotic. The broad band located at $3366 \mathrm{~cm}^{-1}$ is associated with the overlap of phenol, amine, and amide signals. The methyl $\mathrm{CH}$ stretching vibration appears at $2969 \mathrm{~cm}^{-1}$, the band at $1767 \mathrm{~cm}^{-1}$ can be associated with $\beta$-lactam $\mathrm{CO}$ stretch, and the signal at $1670 \mathrm{~cm}^{-1}$ is assigned to amide I, CO stretch. The peak at $1604 \mathrm{~cm}^{-1}$ is related to $\mathrm{COO}^{-}$asymmetric stretch. The band at $1511 \mathrm{~cm}^{-1}$ is attributed to the combination of amide II, 

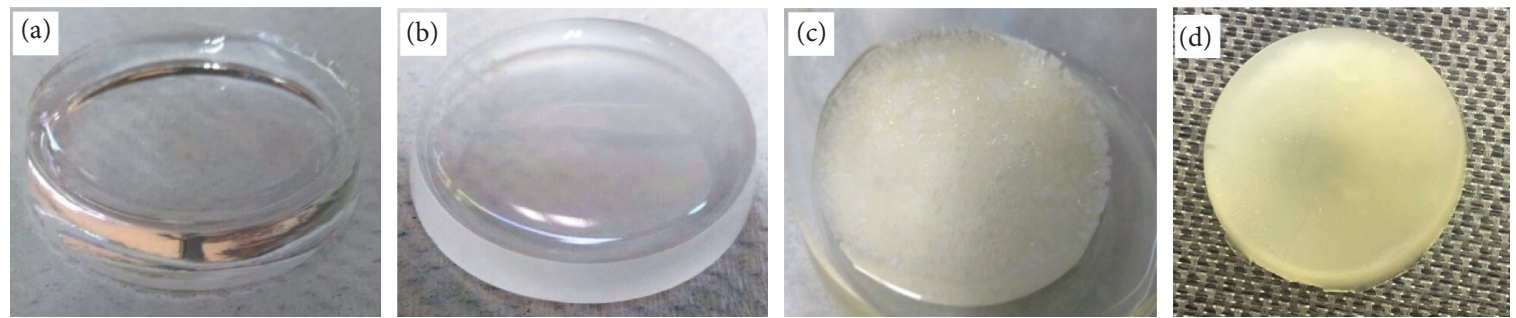

Figure 3: Hydrogel of PAAm/starch: (a) PAAm/starch 100/0; (b) PAAm/starch 50/50; (c) PAAm/starch 50/50 loaded with amoxicillin lyophilized; (d) PAAm/starch 50/50 after drug release in buffer solution ( $\mathrm{pH} 3.0$ ).

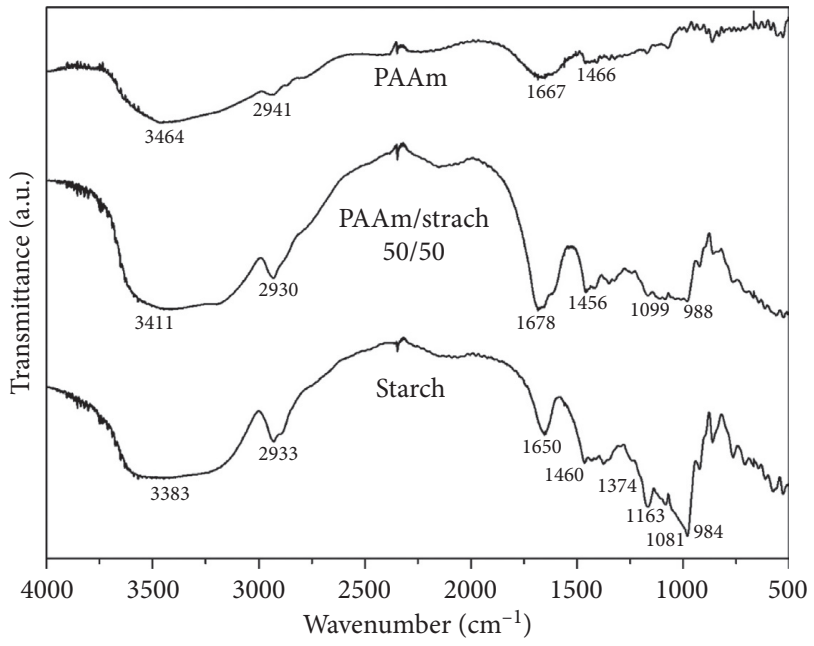

FIGURE 4: FTIR spectrum of PAAm hydrogel, pure starch, and PAAm/starch hydrogel 50/50.

$\mathrm{NH}$ bend $\mathrm{CN}$ stretch, and benzene ring $\mathrm{C}=\mathrm{C}$ stretch bands. The signal at $1458 \mathrm{~cm}^{-1}$ is assigned to $\mathrm{Gem}$ dimethyl $\mathrm{CH}$ deformation, while the peak at $1399 \mathrm{~cm}^{-1}$ is related to $\mathrm{COO}^{-}$ symmetric stretch and phenol $\mathrm{OH}$ moiety. The signal at $1252 \mathrm{~cm}^{-1}$ is assigned to phenol CO combination band, amide III, NH bend, and CN stretch in plane combination bands. The absorption bands at 1173 and $1129 \mathrm{~cm}^{-1}$ can be assigned to benzene ring $\mathrm{CH}$ in plane deformation [54].

The incorporation of amoxicillin to the hydrogels produced the appearance of new bands on the base spectra of PAAm/starch networks. In the hydrogel 50/50, the broad band that appears at $1678 \mathrm{~cm}^{-1}$ in the hydrogel without drug is replaced by a wider band with two small peaks at 1670 and $1604 \mathrm{~cm}^{-1}$ attributed to the amide I, $\mathrm{CO}$ stretch, and $\mathrm{COO}^{-}$ asymmetric stretch signals of amoxicillin. The band at $1399 \mathrm{~cm}^{-1}$ related to $\mathrm{COO}^{-}$symmetric stretch and phenol $\mathrm{OH}$ vibration in the amoxicillin spectrum appears at a shorter wavenumber $\left(1390 \mathrm{~cm}^{-1}\right)$ in the spectra of $50 / 50$ and $100 / 0$ hydrogels. The peak at $1254 \mathrm{~cm}^{-1}$ of hydrogel $50 / 50$ assigned to phenol CO combination band and amide III of amoxicillin was not observed in the spectrum of 50/50 hydrogel. In addition, the signal at $1129 \mathrm{~cm}^{-1}$ associated with benzene ring $\mathrm{CH}$ in plane deformation in the amoxicillin spectrum appears slightly at a shorter wavenumber $\left(1122 \mathrm{~cm}^{-1}\right)$ in the spectra of 50/50 and $100 / 0$ hydrogels, which suggest some physical interaction between the antibiotic and the polymeric matrix, e.g., hydrogen bonds.
Moreover, in the FTIR 100/0 hydrogels spectrum, the two bands associated with the amide I, CO stretch, and $\mathrm{COO}^{-}$asymmetric stretch (1670 and $1604 \mathrm{~cm}^{-1}$ ) appear more defined than that in the spectrum of hydrogel 50/50. The bands at 1390,1254 , and $1124 \mathrm{~cm}^{-1}$ were associated with the amoxicillin signals. These bands were less defined than in the spectrum of 50/50 hydrogel.

3.2. Morphology Characterization. The morphology of hydrated hydrogels of PAAm (100/0) and PAAm/starch (50/50) is shown in Figure 6. PAAm hydrated hydrogel (100/0) exhibits an irregular porous structure of interconnected pores with diameters in the micrometer range (Figures 6(a) and 6(b)). This description is consistent with previous reports related to PAAm-containing hydrogels [55]. The incorporation of starch within the PAAm matrix produces a uniform porous structure with pore diameters in the same micrometer range but slightly larger than those observed in the pure PAAm matrix (Figures 6(c) and 6(d)). In particular, the interaction between both polymers is confirmed by the presence of starch granules embedded in the PAAm network. The starch chains (soluble part) and the granules (water insoluble) are trapped within the PAAm network by physical interactions such as hydrogen bridges (Figure 1). Similar morphological results were reported by Sethi et al. [33] for hydrogels of karaya gum and starch. The suitable modification of the polymer network by the starch incorporation is a desired effect to improve the swelling behavior of materials and its drug release efficiency [56].

Figure 7 shows the SEM images of dry hydrogels of PAAm/starch (50/50) without and with amoxicillin. The micrograph of drug-free composite hydrogel (Figures 7(a) and 7(b)) shows a compact, rugose, and interconnected internal structure with heterogeneous pores. The images also confirmed that the starch granules are randomly distributed within the PAAm matrix, achieving sizes between 9 and $46 \mu \mathrm{m}$. The micrograph of amoxicillin-loaded composite hydrogel (Figures 7(c) and 7(d)) shows that the antibiotic is heterogeneously distributed in the polymer matrix, forming agglomerates that appear as white dots. Similar results were reported by Hanna and Saad [56] for xanthan gum/chitosan hydrogels loaded with ciprofloxacin, in which a random distribution of the drug within the pores was observed.

3.3. Energy-Dispersive X-Ray Spectroscopy (EDX). The elemental analysis of the cross section of composite hydrogel (50/50) loaded with amoxicillin was carried out in situ using 


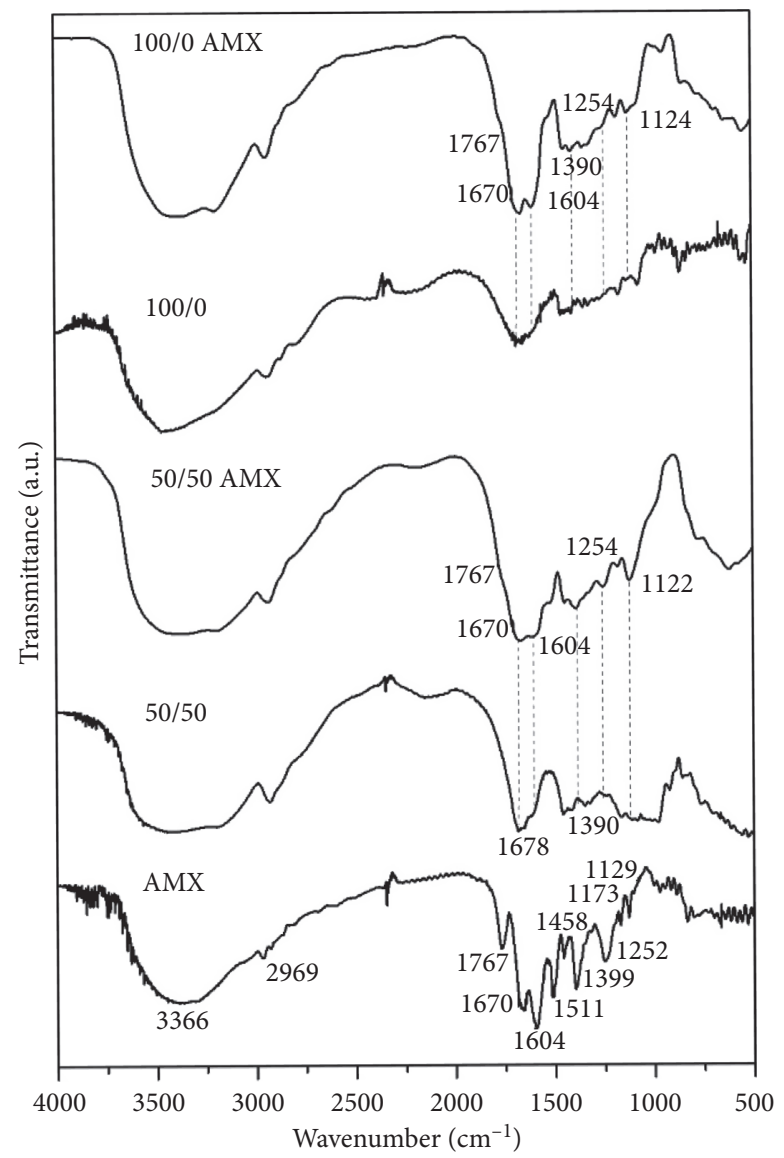

FIGURE 5: FTIR spectrum of hydrogels: 100/0 AMX, PAAm/starch 100/0 amoxicillin-loaded; 100/0, PAAm/starch 100/0 drug-free; 50/50 AMX, PAAm/starch 50/50 amoxicillin-loaded; 50/50, PAAm/starch 50/50 drug-free; AMX, amoxicillin pure.

the energy-dispersive $\mathrm{X}$-ray spectroscopy instrument in conjunction with the SEM (Figure 8). The characterization of elemental composition revealed the presence of $\mathrm{C}, \mathrm{O}, \mathrm{N}$, $\mathrm{Na}$, and $\mathrm{S}$. The content of $\mathrm{S}$ and $\mathrm{Na}$ confirmed the incorporation of amoxicillin into the hydrogel. The $S$ forms part of the structure of the thiazolidine ring (6-aminopenicillanic acid) characteristic of penicillin derivatives [44], and $\mathrm{Na}$ is attributed to the salt form of amoxicillin.

3.4. Swelling Behavior. The swelling curves of hydrogels of different PAAm/starch ratios show that the formulations have a typical swelling behavior, as described elsewhere (Figure 9). A gradual increase in swelling was observed within the first $10 \mathrm{~h}$ that was stabilized after $30 \mathrm{~h}$. The maximum swelling percentage was reached around $48 \mathrm{~h}$ without significant variations afterwards. Our results showed that the increase in the starch content increases the rate of water uptake and the swelling degree at equilibrium. The hydrogels with the highest starch content increased their weights about 6 times during the swelling studies at $\mathrm{pH} 7.4$. The adjustment to volume restrictions in a specific application can be achieved by choosing the appropriate initial mass and shape of hydrogel.

Several factors affect the swelling behavior of hydrogels such as the hydrophilic nature of polymer network, the crosslinking density, and the elasticity of polymer network [38, 57]. Starch addition enhances the hydrophilic nature of polymeric system, positively influencing its swelling capacity. The amylose chains of biopolymer contain a terminal group - $\mathrm{OH}(\mathrm{C1})$ at the reducing end and a $-\mathrm{OH}(\mathrm{C} 4)$ at the nonreducing end of the macromolecule. Thus, each glucose residue of the amylose has two secondary hydroxyl groups on the $\mathrm{C} 2$ and $\mathrm{C} 3$ carbons and a primary hydroxyl group on the C6 carbon. The hydroxylenriched structure of the starch should promote a more significant water retention within the polymer matrix, by increasing the content of the biopolymer in the composite hydrogel. Murthy et al. [38] found a similar behavior after increasing the starch ratio in the poly(acrylamide-co-sodium methacrylate) network. The authors attributed this behavior to the nature of the chemical groups incorporated $\left(-\mathrm{COO}-\mathrm{Na}^{+}\right)$as well as the starch distribution into the gel networks.

A high swelling capacity is a desirable feature for drug delivery applications [58]. The swelling behavior of the polymer matrix can control the drug release from it [59]. The swelling capacity is positively correlated with the amount of drug release at equilibrium [60].

3.5. Amoxicillin Release. Hydrogels of PAAm/starch $60 / 40$ and 50/50 were selected to assess their amoxicillin release kinetics because both formulations efficiently absorbed 

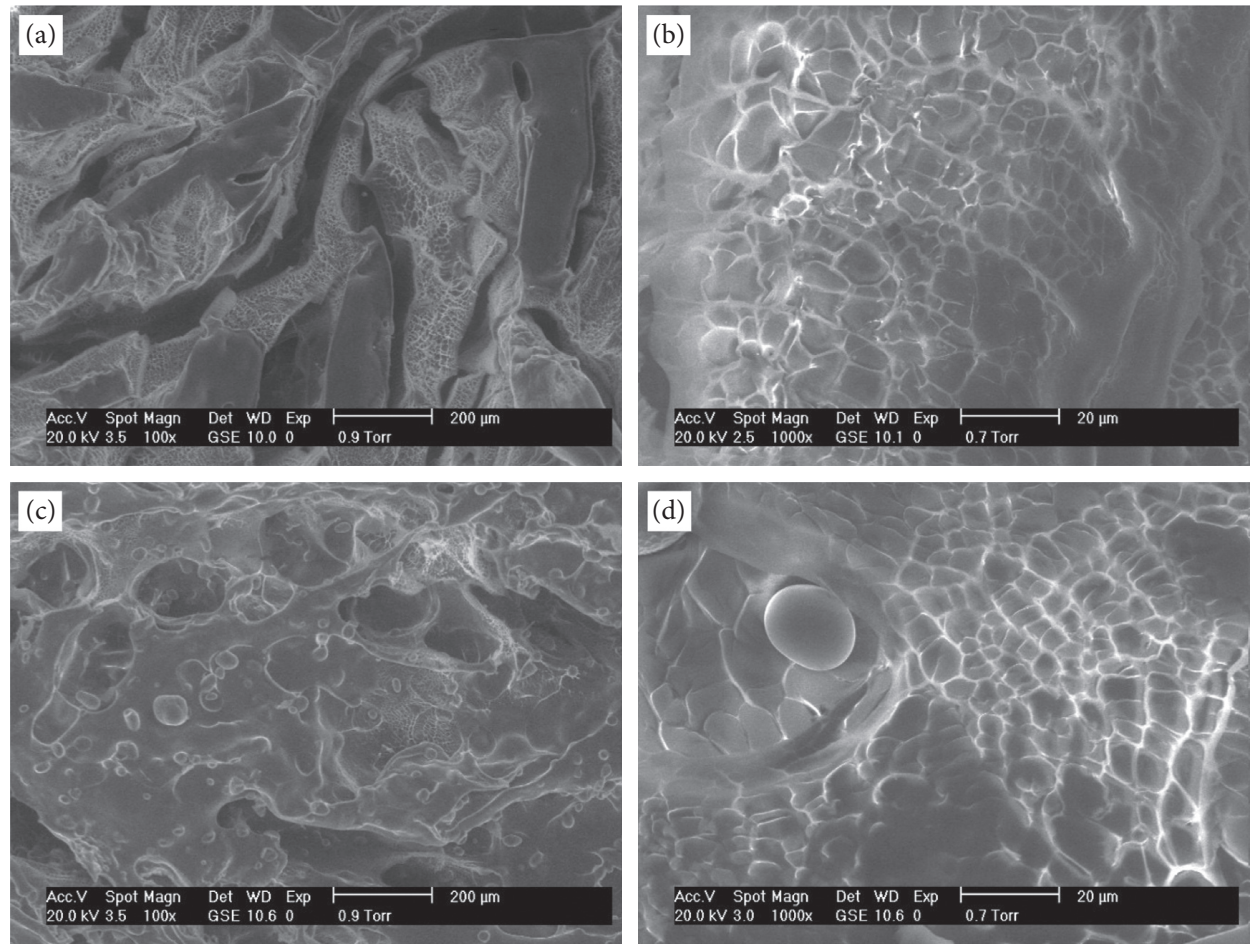

FiguRE 6: SEM micrographs of cross-sections of PAAm/starch hydrated hydrogels: (a) 100/0 at $200 \mu \mathrm{m}$; (b) $100 / 0$ at $20 \mu \mathrm{m}$; (c) $50 / 50$ at $200 \mu \mathrm{m}$; (d) $50 / 50$ at $20 \mu \mathrm{m}$.
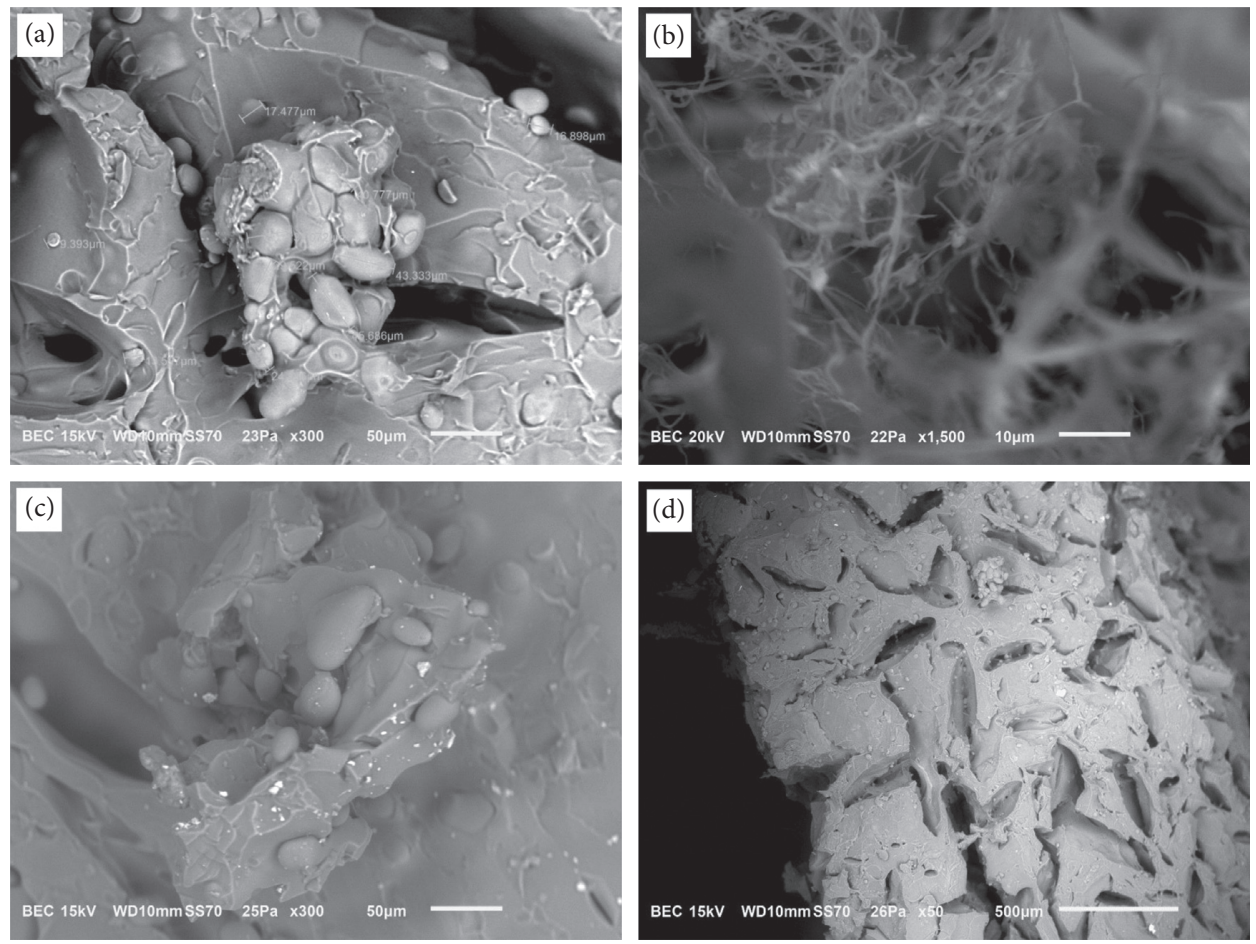

FIGURE 7: SEM micrographs of cross-sections of PAAm/starch dry hydrogels (50/50): (a) drug-free composite hydrogel at $50 \mu \mathrm{m}$; (b) drugfree composite hydrogel at $10 \mu \mathrm{m}$; (c) amoxicillin-loaded composite hydrogel at $50 \mu \mathrm{m}$; (d) amoxicillin-loaded composite hydrogel at $500 \mu \mathrm{m}$. 

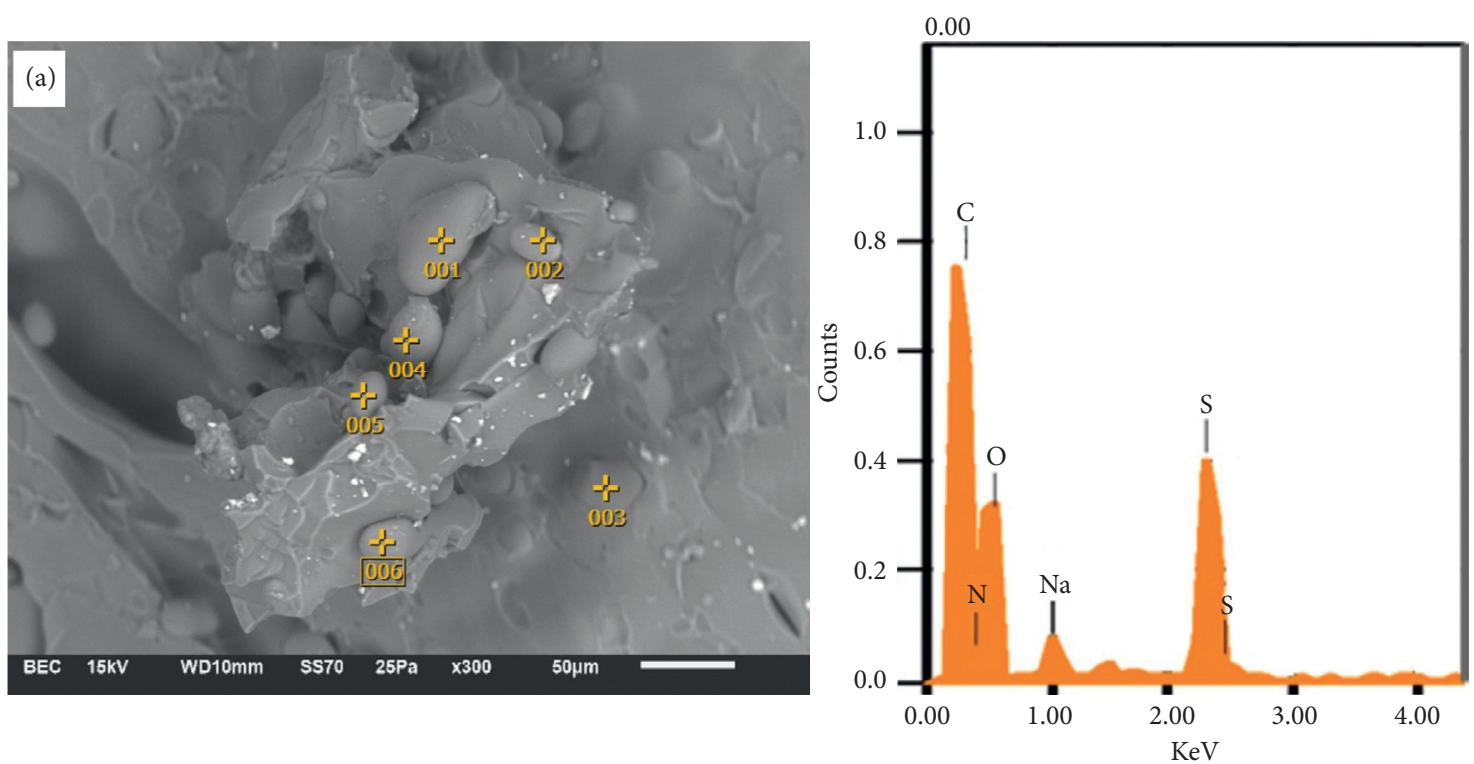

(b)

FIGURE 8: EDX spectrogram of PAAm/starch 50/50 hydrogel loaded with amoxicillin: (a) SEM image; (b) EDX spectrogram.

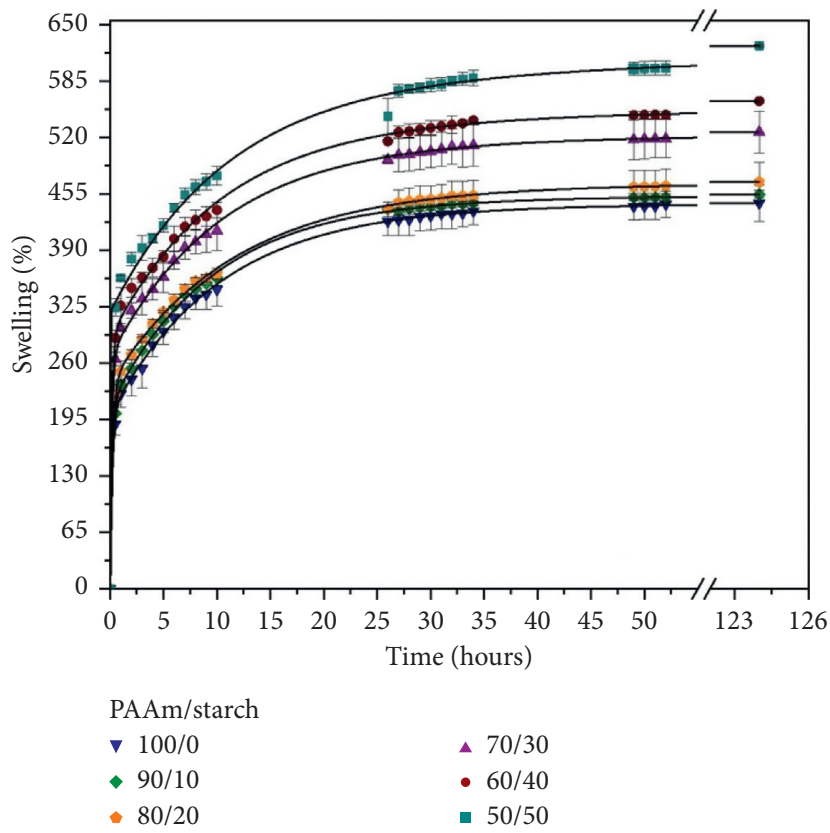

Figure 9: Swelling kinetics as function of time for hydrogels of PAAm/starch in PBS, pH 7.4 with different compositions. The error bars represent the standard deviation $(n=3)$.

around $5 \mathrm{~mL}$ of an aqueous solution of amoxicillin $(0.2 \mathrm{~g}$ $\mathrm{mL}^{-1}$ therapeutic dose) [61]. The loading efficiency was found to be of $78.0 \pm 2.2 \%(0.78 \pm 0.02 \mathrm{~g})$ and $98.6 \pm 2.0 \%$ $(98.6 \pm 2.0 \mathrm{~g})$ in composite hydrogels $60 / 40$ and $50 / 50$, respectively, calculated as the mass ratio of absorbed amoxicillin to the drug mass initially placed in contact with hydrogels after $48 \mathrm{~h}$. The hydrogels conserved its shape and stiffness after the drug loading and changed from a translucent to a uniform yellowish coloration due to the antibiotic content (Figure 3(c)). The drug release profiles from composite hydrogels $60 / 40$ and $50 / 50$ at a temperature of $25^{\circ} \mathrm{C}$ and $\mathrm{pH} 3.0$ are shown in Figure 10. The delivery behavior of both formulations was quite similar; however, it is notorious that the amount of amoxicillin released at equilibrium varied with respect to the polymer matrix composition. The $50 / 50$ hydrogel released $48.6 \%$ of its drug content within the first $24 \mathrm{~h}$, a value significantly higher $(P<0.05)$ than the amount achieved by the $60 / 40$ hydrogel (43.0\%). This behavior can be attributed to the hydrophilic character of the starch. The swelling rate of the hydrogel affects the 


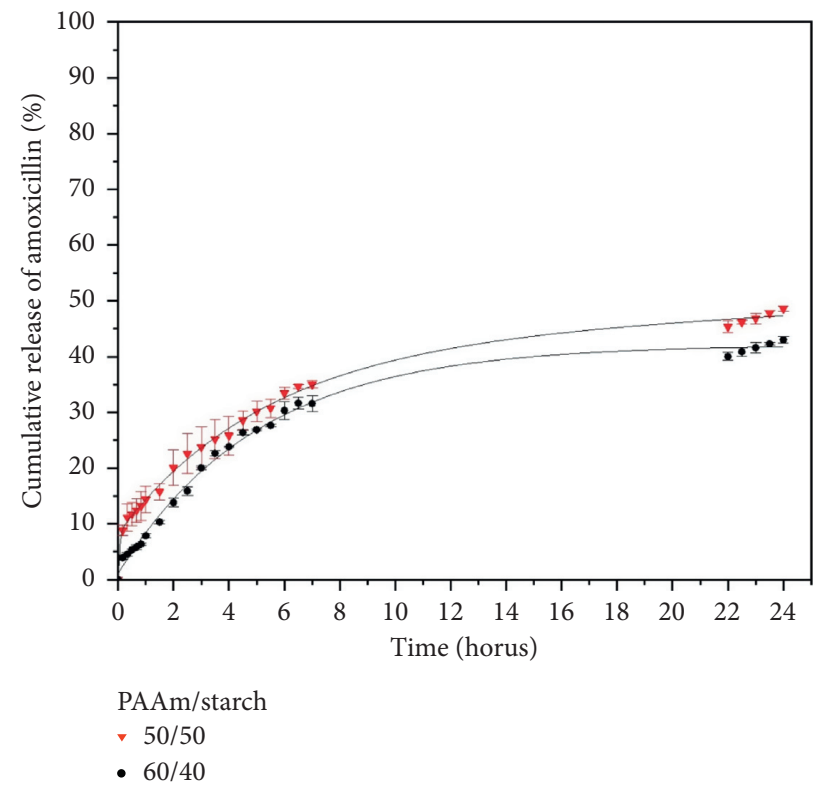

Figure 10: Cumulative release of amoxicillin from composite hydrogels PAAm/starch 60/40 and 50/50 in PCA, pH 3.0 at $25^{\circ} \mathrm{C}$. The error bars represent the standard deviation $(n=3)$.

kinetic of drug release [59]. The hydrogel of a higher starch content contains a larger number of hydrophilic hydroxyl groups, which results in a greater degree of hydration. This effect favors the antibiotic release from the hydrogel [58]. In this concern, PAAm/starch 50/50 network showed a more efficient amoxicillin release as compared with PAAm/starch 60/40 matrix. These observations are consistent with swelling behavior results. It should be noted that the hydrogel preserved its physical integrity after the amoxicillin release in the buffer solution (Figure 3).

3.5.1. Effect of Temperature on Amoxicillin Release. Based on our previous result, the composite hydrogel 50/50 was selected to assess the effect of temperature and $\mathrm{pH}$ on amoxicillin release kinetics. Figure 11 shows the temperature effect on the amoxicillin release from the composite hydrogel. The release profiles were similar for both temperatures, and the amount released of amoxicillin increased rapidly within the first hours, reaching the equilibrium around the $22 \mathrm{~h}$. However, statistically significant differences of release percentages at equilibrium were found between both temperature conditions. It was possible to release approximately $48.6 \%(0.471 \mathrm{~g})$ of the antibiotic at $25^{\circ} \mathrm{C}$. Instead, this percentage increased to $70.2 \%$ by increasing the temperature of the release medium to $37^{\circ} \mathrm{C}$, amount equivalent to $0.680 \mathrm{~g}$ of the amoxicillin contained in the hydrogel. This behavior can be attributed to the dissociation of physical interactions, such as hydrogen bonds between PAAm chains and starch chains, with the rise of temperature, which decreases the crosslinking density of the polymer matrix and favors the release of the solute [62]. Additionally, by increasing the temperature in the release system, the kinetic energy of the drug molecules is also increased, increasing the probability of breaking the physical interactions of the antibiotic with the polymer system. The coefficient and diffusion rate of amoxicillin from the polymer matrix to the release medium increases as the temperature rises [62].

3.5.2. Effect of $p H$ on Amoxicillin Release. In previous researches, the sustained release of drugs has been studied in vitro in acid media and in more basic conditions to evaluate the release behavior of dosage forms in the stomach $(\mathrm{pH}$ 1-3) [63], small intestine [14, 64], and oral mucosa-like environments ( $\mathrm{pH}$ 7.4) [65]. Figure 12 shows the amoxicillin release profiles of the hydrogel PAAm/starch 50/50 at pH 3.0 and 7.4, simulating these $\mathrm{pH}$ conditions.

The maximum values of cumulative release reached around $22 \mathrm{~h}$ in both $\mathrm{pH}$ values, with a statistically significant difference $(P<0.05)$ in the drug concentration. The amoxicillin release percent at equilibrium was relatively higher at basic $\mathrm{pH}(81.0 \%)$ as compared with the percentage released in the acidic medium (70.2\%). The variation in the released amount with the $\mathrm{pH}$ can be attributed to the protonation or deprotonation of the amino, carboxyl, and phenolic groups present in the amoxicillin. The $\mathrm{pK}_{\mathrm{a}}$ values of the ionizable groups of amoxicillin are 2.67, 7.11, and 9.55 for amino, carboxyl, and phenolic moieties, respectively $[44,66]$. This means that, at $\mathrm{pH} 3.0$, the carboxyl groups are partially deprotonated $\left(-\mathrm{COO}^{-}\right)$, the amino groups are protonated $\left(-\mathrm{NH}_{3}{ }^{+}\right)$, and phenolic groups are in the neutral state $(\mathrm{pH}-\mathrm{OH})$. This partial ionization of amoxicillin can cause the breakdown of some of the hydrogen bridge interactions that keep the molecule bounded to the polymer network, favoring its release. The interaction of charged antibiotic molecules with the buffer ions can also promote the drug release. As the $\mathrm{pH}$ of the release medium ( $\mathrm{pH}$ 7.4) increases, the amino $\left(-\mathrm{NH}_{3}{ }^{+}\right)$and phenolic $(\mathrm{pH}-\mathrm{OH})$ 


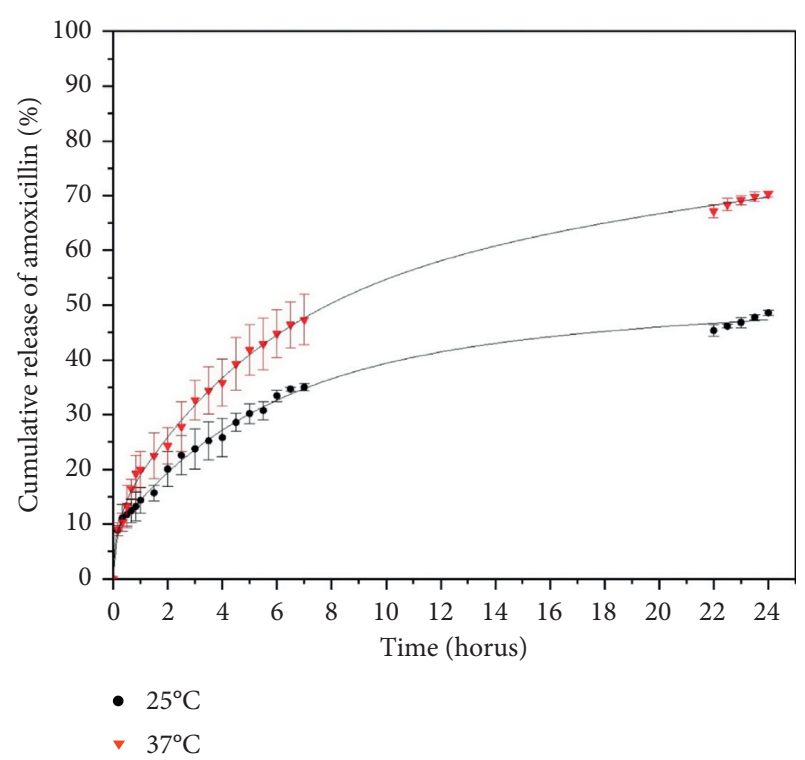

Figure 11: Cumulative release of amoxicillin from composite hydrogels PAAm/starch 50/50 in PCA, pH 3.0 at $25^{\circ} \mathrm{C}$ and $37^{\circ} \mathrm{C}$. The error bars represent the standard deviation $(n=3)$.

groups remain protonated, while the percentage of ionization of the carboxyl groups increases, which can cause the breakdown of the interactions between the amoxicillin molecules and the polymer matrix and a higher percentage of antibiotic release at this $\mathrm{pH}$ value [66]. It should also be considered that the solubility of amoxicillin increases at a more basic $\mathrm{pH}$. Sutherland et al. [67] found that amoxicillin solubility increases to a higher $\mathrm{pH}$. The $\mathrm{pH}$-sensitive drug release has been typically observed for chitosan $[60,68]$, poly(methacrylic acid) (PMAA) [64], and polyacrylamide [49] hydrogels. Table 1 summarizes the amoxicillin release amounts from composite hydrogel PAAm/starch 50/50 at $24 \mathrm{~h}$.

3.6. Mechanism and Mathematical Modeling for Amoxicillin Release from PAAm/Starch Hydrogels. The mechanism of drug release from hydrogels is determined by different physical-chemical phenomena [10]. To further examine the release mechanism of amoxicillin from the composite hydrogels, the experimental data were fitted to the model developed by Korsmeyer-Peppas. According to this model for cylinder-shaped gels, the drug release mechanism depends on the relative rate of water diffusion into the polymer matrix and the rate of polymer chain relaxations. When $n$ is less than 0.45 , the transport mechanism is governed by Fickian diffusion (the release mechanism is diffusion controlled). When $n$ is between 0.45 and 0.89 , the process follows an anomalous transport mechanism, a mixture of both Fickian diffusion and polymer chain relaxation. For $n$ equal to 0.89 , a case II transport occurs (the release mechanism is relaxation controlled) [4]. The linear fit of the plot $\ln M t / M_{\infty}$ against $\ln t$ yields the diffusion exponent $(n)$, the Pearson coefficient $\left(r^{2}\right)$, and the diffusion constant $(k)$. The results are summarized in Table 2.

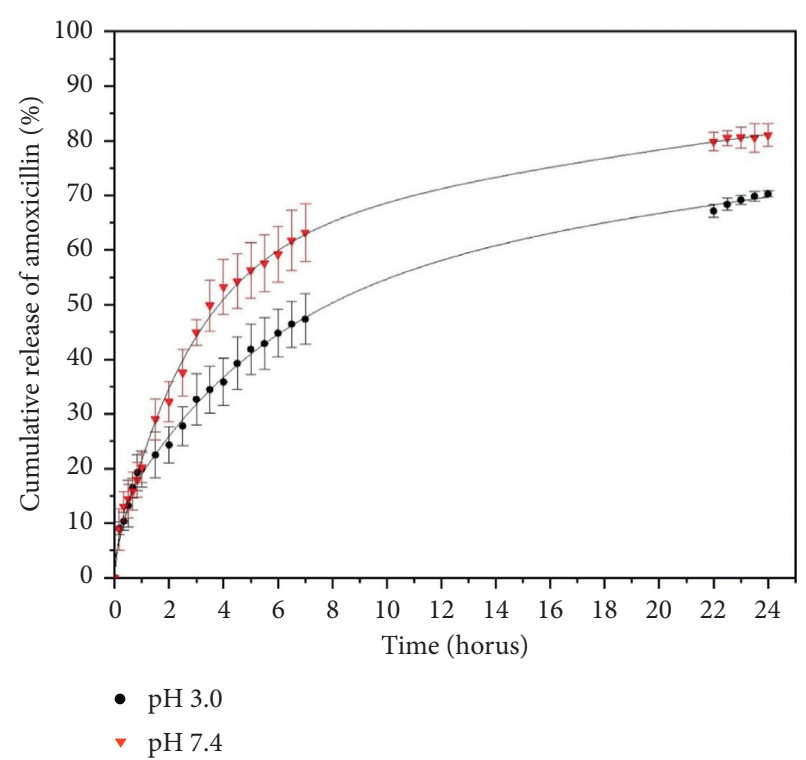

FIgURE 12: Cumulative release of amoxicillin from composite hydrogel PAAm/starch 50/50 in PCA, pH 3.0, and PBS, pH 7.4 at $37^{\circ} \mathrm{C}$. The error bars represent the standard deviation $(n=3)$.

TABLE 1: Quantification of amoxicillin release from composite hydrogel of PAAm/starch 50/50 at different temperatures and $\mathrm{pH}$ values.

\begin{tabular}{lccc}
\hline & & \multicolumn{3}{c}{ Amoxicillin release after } \\
Temperature $\left({ }^{\circ} \mathrm{C}\right)$ & $\mathrm{pH}$ & & $24 \mathrm{~h}$ \\
& & $\%$ & $\mathrm{mg}$ \\
\hline 25 & 3.0 & $48.6 \pm 0.5$ & $466 \pm 5.4$ \\
37 & 3.0 & $70.2 \pm 0.6$ & $702 \pm 6.1$ \\
& 7.4 & $81.0 \pm 2.1$ & $810 \pm 21.2$ \\
\hline
\end{tabular}

Values are presented as means \pm standard deviation.

The amoxicillin released from hydrogel $50 / 50$ at $37^{\circ} \mathrm{C}$ is controlled by an anomalous transport mechanism, a mixture of both Fickian diffusion and relaxation process of the polymer chains by the water absorption. No apparent effect of $\mathrm{pH}$ on the mechanism of amoxicillin transport was observed.

3.7. Bacterial Growth Inhibition Assay. To evaluate inhibition of bacterial growth by the released amoxicillin, polymeric hydrogels (50/50 PAAm/starch) were prepared, with dimensions similar to that of a commercial disc: $6 \mathrm{~mm}$ in diameter and $3 \mathrm{~mm}$ thick.

Antibacterial activity of PAAm/starch hydrogels loaded with amoxicillin was evaluated by growth inhibition of Escherichia coli ATCC 25922, Staphylococcus aureus ATCC 25923, and a carbapenemase producer, and amikacin-resistant, Pseudomonas aeruginosa strain. Figure 13 shows bacterial growth after 24 hours of incubation at $37^{\circ} \mathrm{C}$. All hydrogels showed inhibition of bacterial growth except for the resistant strain ( $P$. aeruginosa) and the hydrogels used as control (without amoxicillin), which indicates that the hydrogel itself did not have antimicrobial activity. The 
TABLE 2: Fitting parameters of amoxicillin release data to Korsmeyer-Peppas equation for hydrogels under different conditions.

\begin{tabular}{|c|c|c|c|c|c|}
\hline \multirow{2}{*}{ Hydrogel PAAm/starch } & \multirow{2}{*}{ Conditions } & \multicolumn{3}{|c|}{ Fitting parameters } & \multirow{2}{*}{ Release mechanism } \\
\hline & & $n$ & $k\left(10^{-2}\right)$ & $r^{2}$ & \\
\hline \multirow{2}{*}{$50 / 50$} & $\mathrm{pH} 3.0,37^{\circ} \mathrm{C}$ & 0.46 & 4.11 & 0.988 & Anomalous transport \\
\hline & $\mathrm{pH} 7.4,37^{\circ} \mathrm{C}$ & 0.57 & 2.62 & 0.976 & Anomalous transport \\
\hline
\end{tabular}
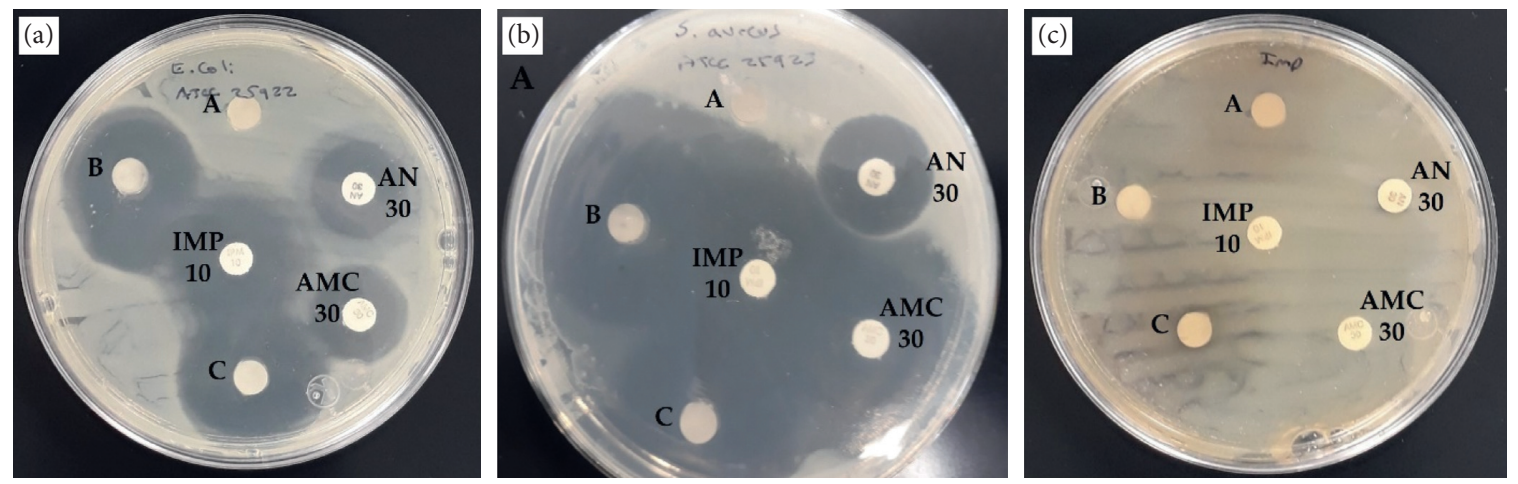

Figure 13: Growth inhibition effect of the PAAm/starch hydrogels against (a) E. coli ATCC 25922, (b) S. aureus ATCC 25923, and (c) carbapenemase producer, and amikacin-resistant, $P$. aeruginosa, after incubating at $37^{\circ} \mathrm{C}$ for $24 \mathrm{~h}$. A: hydrogel without drug (negative control); B: hydrogel loaded with $600 \mu \mathrm{g}$ amoxicillin; C: loaded with $1200 \mu \mathrm{g}$ amoxicillin; AN: amikacin (30 $\mu \mathrm{g}) ;$ AMC: amoxicillin/clavulanic acid $(20 / 10 \mu \mathrm{g})$; IMP: imipenem $(10 \mu \mathrm{g})$.

Table 3: Average of inhibition diameters zone from amoxicillin-loaded hydrogels and commercial discs.

\begin{tabular}{|c|c|c|c|c|c|c|}
\hline \multirow{3}{*}{ Strain } & \multicolumn{6}{|c|}{ Inhibition zone (mm) } \\
\hline & \multicolumn{3}{|c|}{ Amoxicillin load $(\mu \mathrm{g})$} & \multirow{2}{*}{$\begin{array}{c}\text { Amoxicillin/clavulanic } \\
\text { acid }(\mu \mathrm{g}) \\
20 / 10\end{array}$} & \multirow{2}{*}{$\begin{array}{l}\text { Amikacin } \\
(\mu \mathrm{g}) \\
30\end{array}$} & \multirow{2}{*}{$\begin{array}{c}\text { Imipenem } \\
(\mu \mathrm{g}) \\
10 \\
\end{array}$} \\
\hline & 0 & 600 & 1200 & & & \\
\hline E. coli ATCC 25922 & $0 \pm 0$ & $28 \pm 0.47$ & $32 \pm 1.70$ & $19 \pm 0$ & $22 \pm 0.47$ & $30 \pm 0$ \\
\hline S. aureus ATCC 25923 & $0 \pm 0$ & $40 \pm 0$ & $40 \pm 0$ & $34 \pm 1.63$ & $20 \pm 0.47$ & N/A \\
\hline $\begin{array}{l}\text { Carbapenemase producer, and amikacin-resistant, } \\
\text { P. aeruginosa }\end{array}$ & $0 \pm 0$ & $0 \pm 0$ & $0 \pm 0$ & $0 \pm 0$ & $0 \pm 0$ & $0 \pm 0$ \\
\hline
\end{tabular}

Values are presented as means \pm standard deviation.

absence of growth inhibition for carbapenemase producer Pseudomonas aeruginosa (Figure 13(c)) is expected since this strain produces $b l a_{I M P-18}$, a metallo-b-lactamase, with high catalytic efficiency for the hydrolysis of $\beta$-lactam antibiotics, including carbapenems [69].

Table 3 shows an average of the inhibition diameters for the amoxicillin-loaded hydrogels and commercial discs. Each experiment was carried out in triplicate. As expected, the results show that the loaded hydrogels were more effective against the $S$. aureus (Gram-positive) than against E. coli (Gram-negative). These results were logical since amoxicillin acts on the exposed layer of peptidoglycan wall of Gram-positive bacteria. Instead, Gram-negative bacteria have an outer layer of lipopolysaccharides and proteins that covers the peptidoglycan layer, and this makes it difficult for some antibiotics to achieve the bacterial peptidoglycan.

The imipenem is a carbapenem drug, and carbapenems are drugs with a greater bactericidal activity and are not affected for most of the bacterial $\beta$-lactamases [70]. Hydrogel discs showed a greater zone of inhibition compared to commercial disc of amikacin, an aminoglycoside, recommended by manufacturer and based on CLSI recommendations (19-26 mm for E. coli and $20-26 \mathrm{~mm}$ for S. aureus).

Similar results were reported for other bacterial strains (same genera and species) from hydrogels of $N$-trimethyl chitosan (TMC)/sodium carboxymethyl xanthan gum (CMXG) prepared with ciprofloxacin [56]. A similar study, with $S$. aureus and $P$. aeruginosa (different strains than the used in this work), also showed inhibition zones when the authors used hydrophilic networks with conjugated betacyclodextrin for the localized release of 5,6-dimethoxy-1indanone N4-allyl thiosemicarbazone [71].

The results obtained in this study strongly demonstrated that the amoxicillin preserves its microbiological activity after being loaded and released from the polymeric matrix.

\section{Conclusions}

Composite hydrogels of PAAm/starch were successfully prepared at different ratios. The incorporation of starch into the PAAm matrix modified the three-dimensional structure 
of PAAm, favoring the swelling properties of material. The formulation of a higher starch content displayed the highest amount of amoxicillin delivered at equilibrium. Moreover, the release kinetic of amoxicillin from the PAAm/starch hydrogels was sensitive to $\mathrm{pH}$ and temperature conditions. Indeed, the antibiotic release was promoted at physiological conditions ( $\mathrm{pH} 7.4,37^{\circ} \mathrm{C}$ ) as compared to the delivery in the acidic medium ( $\mathrm{pH}$ 3.0) and under room temperature conditions. Additionally, the mechanism of drug release is controlled by an anomalous transport. The amoxicillin released from PAAm/starch composite hydrogels exhibited a relevant antibacterial activity against bacterial strains of clinical interest such as E. coli ATCC 25922 and S. aureus ATCC 25923. Our results have shown that the PAAm/starch hydrogels can be considered a potential platform for controlled drug delivery applications, e.g., for the gastrointestinal administration and local treatment of infections.

\section{Data Availability}

The data used to support the findings of this study are included within the article.

\section{Conflicts of Interest}

The authors declare that there are no conflicts of interest.

\section{Acknowledgments}

The authors acknowledge the financial support and the necessary analytical facilities to carry out this research work from the Departamento de Ciencias Químico Biológicas and Departamento de Investigación en Polímeros y Materiales of Universidad de Sonora. The authors also thank Dr. Jesús Silva Sánchez, who provided Pseudomonas aeruginosa, $b l a_{I M P-18}$ producer, strain.

\section{References}

[1] H. Mazaheri, "Study of swelling behavior of temperature sensitive hydrogels considering inextensibility of network," Scientia Iranica, vol. 26, no. 2, pp. 887-896, 2018.

[2] M. K. Lima-Tenório, E. T. Tenório-Neto, M. R. Guilherme et al., "Water transport properties through starch-based hydrogel nanocomposites responding to both $\mathrm{pH}$ and a remote magnetic field," Chemical Engineering Journal, vol. 259, pp. 620-629, 2015.

[3] H. Liu, M. Zhen, and R. Wu, "Ionic-strength- and pH-responsive poly[acrylamide-co-(maleic acid)] hydrogel nanofibers," Macromolecular Chemistry and Physics, vol. 208, no. 8, pp. 874-880, 2007.

[4] A. M. Orduño Rodríguez, C. J. Pérez Martínez, T. del Castillo Castro, M. M. Castillo Ortega, D. E. Rodríguez Félix, and J. Romero García, "Nanocomposite hydrogel of poly(vinyl alcohol) and biocatalytically synthesized polypyrrole as potential system for controlled release of metoprolol," Polymer Bulletin, vol. 77, no. 3, pp. 1217-1232, 2019.

[5] T. Miyata, T. Uragami, and K. Nakamae, "Biomoleculesensitive hydrogels," Advanced Drug Delivery Reviews, vol. 54, no. 1, pp. 79-98, 2002.
[6] E. Gil and S. Hudson, "Stimuli-reponsive polymers and their bioconjugates," Progress in Polymer Science, vol. 29, no. 12, pp. 1173-1222, 2004.

[7] C. He, S. W. Kim, and D. S. Lee, "In situ gelling stimulisensitive block copolymer hydrogels for drug delivery," Journal of Controlled Release, vol. 127, no. 3, pp. 189-207, 2008.

[8] B. Jeong, S. W. Kim, and Y. H. Bae, "Thermosensitive sol-gel reversible hydrogels," Advanced Drug Delivery Reviews, vol. 64, pp. 154-162, 2012.

[9] B. Biduski, W. M. F. d. Silva, R. Colussi et al., "Starch hydrogels: the influence of the amylose content and gelatinization method," International Journal of Biological Macromolecules, vol. 113, pp. 443-449, 2018.

[10] F. Sabbagh and I. I. Muhamad, "Acrylamide-based hydrogel drug delivery systems: release of Acyclovir from $\mathrm{MgO}$ nanocomposite hydrogel," Journal of the Taiwan Institute of Chemical Engineers, vol. 72, pp. 182-193, 2017.

[11] H. Xue, L. Hu, Y. Zhu et al., "Quaternized chitosan-Matrigelpolyacrylamide hydrogels as wound dressing for wound repair and regeneration," Carbohydrate Polymers, vol. 226, Article ID 115302, 2019.

[12] L. Nie, J. Zou, M. Sun et al., "Injectable vaginal hydrogels as a multi-drug carrier for contraception," Applied Sciences, vol. 9, no. 8, pp. 1638-1721, 2019.

[13] Y. Zhang, J. Yu, K. Ren, J. Zuo, J. Ding, and X. Chen, "Thermosensitive hydrogels as scaffolds for cartilage tissue engineering," Biomacromolecules, vol. 20, no. 4, pp. 1478-1492, 2019.

[14] A. Abaee, M. Mohammadian, and S. M. Jafari, "Whey and soy protein-based hydrogels and nano-hydrogels as bioactive delivery systems," Trends in Food Science and Technology, vol. 70, pp. 69-81, 2017.

[15] M. F. Maitz, U. Freudenberg, M. V. Tsurkan, M. Fischer, T. Beyrich, and C. Werner, "Bio-responsive polymer hydrogels homeostatically regulate blood coagulation," $\mathrm{Na}$ ture Communications, vol. 4, no. 1, pp. 1-7, 2013.

[16] E. S. Dragan, "Design and applications of interpenetrating polymer network hydrogels. A review," Chemical Engineering Journal, vol. 243, pp. 572-590, 2014.

[17] C. Wang, X. Guan, Y. Yuan, Y. Wu, and S. Tan, "Polyacrylamide crosslinked by bis-vinylimidazolium bromide for high elastic and stable hydrogels," RSC Advances, vol. 9, no. 47, pp. 27640-27645, 2019.

[18] A. Tangri, "Polyacrylamide based hydrogels: synthesis, characterization and applications," International Journal of Pharmaceutical Chemical and Biological Sciences, vol. 4, no. 4, pp. 951-959, 2014.

[19] C. Martín, S. Merino, J. M. González-Domínguez et al., "Graphene improves the biocompatibility of polyacrylamide hydrogels: 3D polymeric scaffolds for neuronal growth," Scientific Reports, vol. 7, no. 1, pp. 1-12, 2017.

[20] S. B. Patil, S. Z. Inamdar, K. R. Reddy, A. V. Raghu, S. K. Soni, and R. V. Kulkarni, "Novel biocompatible poly(acrylamide)grafted-dextran hydrogels: synthesis, characterization and biomedical applications," Journal of Microbiological Methods, vol. 159, pp. 200-210, 2019.

[21] S. F. Chou, L. J. Luo, and J. Y. Lai, "Gallic acid grafting effect on delivery performance and antiglaucoma efficacy of antioxidant-functionalized intracameral pilocarpine carriers," Acta Biomaterialia, vol. 38, pp. 116-128, 2016.

[22] C. J. Pérez-Martínez, S. D. Morales Chávez, T. del CastilloCastro et al., "Electroconductive nanocomposite hydrogel for 
pulsatile drug release," Reactive and Functional Polymers, vol. 100, pp. 12-17, 2016.

[23] Z. Yang, H. Peng, W. Wang, and T. Liu, "Crystallization behavior of poly( $\varepsilon$-caprolactone)/layered double hydroxide nanocomposites," Journal of Applied Polymer Science, vol. 116, no. 5, pp. 2658-2667, 2010.

[24] B. B. Mandal, S. Kapoor, and S. C. Kundu, "Silk fibroin/ polyacrylamide semi-interpenetrating network hydrogels for controlled drug release," Biomaterials, vol. 30, no. 14, pp. 2826-2836, 2009.

[25] M. E. S. Miranda, C. Marcolla, C. A. Wilhelm et al., "Chitosan andN-carboxymethylchitosan: I. The role ofN-carboxymethylation of chitosan in the thermal stability and dynamic mechanical properties of its films," Polymer International, vol. 55, no. 8, pp. 961-969, 2006.

[26] J. Wang, X. Zhou, and H. Xiao, "Structure and properties of cellulose/poly( $N$-isopropylacrylamide) hydrogels prepared by SIPN strategy," Carbohydrate Polymers, vol. 94, no. 2, pp. 749-754, 2013.

[27] C. Elvira, J. F. Mano, J. San Román, and R. L. Reis, "Starchbased biodegradable hydrogels with potential biomedical applications as drug delivery systems," Biomaterials, vol. 23, no. 9, pp. 1955-1966, 2002.

[28] F. Muñoz-Muñoz, A. Contreras-García, G. Burillo, and E. Bucio, "Radiación gamma para el diseño de sistemas inteligentes en liberación controlada de fármacos e ingeniería de tejidos," Biomateriais aplicados ao desenvolvimento de sistemas terapêuticos avançados, pp. 485-519, 2015.

[29] F. Kavousi and N. Nikfarjam, "Highly interconnected macroporous structures made from starch nanoparticle-stabilized medium internal phase emulsion polymerization for use in cell culture," Polymer, vol. 180, Article ID 121744, 2019.

[30] G. R. Bardajee and Z. Hooshyar, "One-pot synthesis of biocompatible superparamagnetic iron oxide nanoparticles/ hydrogel based on salep: characterization and drug delivery," Carbohydrate Polymers, vol. 101, no. 1, pp. 741-751, 2014.

[31] G. Muhammad, M. T. Haseeb, M. A. Hussain et al., "Stimuliresponsive/smart tablet formulations (under simulated physiological conditions) for oral drug delivery system based on glucuronoxylan polysaccharide," Taylor and Francis, vol. 46, no. 1, 2020.

[32] D. D. Nguyen, L.-J. Luo, S. J. Lue, and J.-Y. Lai, "The role of aromatic ring number in phenolic compound-conjugated chitosan injectables for sustained therapeutic antiglaucoma efficacy," Carbohydrate Polymers, vol. 231, Article ID 115770, 2020.

[33] S. Sethi, B. S. Kaith, M. Kaur, N. Sharma, and S. Khullar, "Study of a cross-linked hydrogel of Karaya gum and Starch as a controlled drug delivery system," Journal of Biomaterials Science, Polymer Edition, vol. 30, no. 18, pp. 1687-1708, 2019.

[34] F. Soleimani and M. Sadeghi, "Synthesis of pH-sensitive hydrogel based on starch-polyacrylate superabsorbent," Journal of Biomaterials and Nanobiotechnology, vol. 3, no. 2, pp. 310-314, 2012.

[35] A. Dafe, H. Etemadi, A. Dilmaghani, and G. R. Mahdavinia, "Investigation of pectin/starch hydrogel as a carrier for oral delivery of probiotic bacteria," International Journal of Biological Macromolecules, vol. 97, pp. 536-543, 2017.

[36] J. J. Perez, N. J. Francois, G. A. Maroniche, M. P. Borrajo, M. A. Pereyra, and C. M. Creus, "A novel, green, low-cost chitosan-starch hydrogel as potential delivery system for plant growth-promoting bacteria," Carbohydrate Polymers, vol. 202, pp. 409-417, 2018.
[37] S. Shaik, M. R. Kummara, S. Poluru et al., “A green approach to synthesize silver nanoparticles in starch-co-poly(acrylamide) hydrogels by tridax procumbens leaf extract and their antibacterial activity," International Journal of Carbohydrate Chemistry, vol. 2013, Article ID 539636, 10 pages, 2013.

[38] P. S. K. Murthy, Y. M. Mohan, J. Sreeramulu, and K. M. Raju, "Semi-IPNs of starch and poly(acrylamide-co-sodium methacrylate): preparation, swelling and diffusion characteristics evaluation," Reactive and Functional Polymers, vol. 66, no. 12, pp. 1482-1493, 2006.

[39] P. C. Parvathy and A. N. Jyothi, "Synthesis, characterization and swelling behaviour of superabsorbent polymers from cassava starch-graft-poly(acrylamide)," Starch-Stärke, vol. 64, no. 3, pp. 207-218, 2012.

[40] E. S. Dragan and D. F. Apopei, "Synthesis and swelling behavior of $\mathrm{pH}$-sensitive semi-interpenetrating polymer network composite hydrogels based on native and modified potatoes starch as potential sorbent for cationic dyes," Chemical Engineering Journal, vol. 178, pp. 252-263, 2011.

[41] I. Azman, S. A. Mutalib, S. F. M. Fazry et al., "NovelDioscorea hispidastarch-based hydrogels and their beneficial use as disinfectants," Journal of Bioactive and Compatible Polymers, vol. 31, no. 1, pp. 42-59, 2016.

[42] K. Alharbi, A. Ghoneim, A. Ebid, H. El-Hamshary, and M. H. El-Newehy, "Controlled release of phosphorous fertilizer bound to carboxymethyl starch-g-polyacrylamide and maintaining a hydration level for the plant," International Journal of Biological Macromolecules, vol. 116, pp. 224-231, 2018.

[43] A. Zumbuehl, L. Ferreira, D. Kuhn et al., "Antifungal hydrogels," Proceedings of the National Academy of Sciences, vol. 104, no. 32, pp. 12994-12998, 2007.

[44] S. P. Kaur, R. Rao, and S. Nanda, "Amoxicillin: a broad spectrum antibiotic," International Journal of Pharmacy and Pharmaceutical Sciences, vol. 3, no. 3, pp. 30-37, 2011.

[45] C. Chiung-Hung, L. Yu-Hsin, Y. Chia-Lin et al., "Nanoparticles incorporated in $\mathrm{pH}$-sensitive hydrogels as amoxicillin delivery for eradication of Helicobacter pylori," Biomacromolecules, vol. 11, no. 1, pp. 133-142, 2010.

[46] S. Kumar, A. K. Singh, S. K. Prajapati, and V. K. Singh, "Formulation and evaluation of once daily sustained release matrix tablets of Aceclofenac using natural gums," Journal of Drug Delivery and Therapeutics, vol. 2, no. 1, pp. 16-24, 2012.

[47] C. Zhu, J. Zhao, K. Kempe et al., “A hydrogel-based localized release of colistin for antimicrobial treatment of burn wound infection," Macromolecular Bioscience, vol. 17, no. 2, pp. 1600320-1600327, 2017.

[48] R. Liu, S. Liang, X. Z. Tang, D. Yan, X. Li, and Z. Z. Yu, “Tough and highly stretchable graphene oxide/polyacrylamide nanocomposite hydrogels," Journal of Materials Chemistry, vol. 22, no. 28, pp. 14160-14167, 2012.

[49] C. M. Setty, A. S. Deshmukh, and A. M. Badiger, "Hydrolyzed polyacrylamide grafted maize starch based microbeads: application in $\mathrm{pH}$ responsive drug delivery," International Journal of Biological Macromolecules, vol. 70, pp. 1-9, 2014.

[50] E. Turan, S. Demirci, and T. Caykara, "Preparation of polyacrylamide hydrogels at various charge densities by postmodification," Journal of Applied Polymer Science, vol. 111, no. 1, pp. 108-113, 2009.

[51] N. González, J. Contreras, F. López-Carrasquero et al., "Estudio de la síntesis y caracterización de hidrogeles semiIPN obtenidos a partir de poliacrilamida y el biopolímero poli(hidroxibutirato-co-hidroxivalerato)," Interciencia, vol. 38, no. 6, pp. 430-436, 2013. 
[52] C. Spagnol, F. H. A. Rodrigues, A. G. B. Pereira, A. R. Fajardo, A. F. Rubira, and E. C. Muniz, "Superabsorbent hydrogel nanocomposites based on starch-g-poly(sodium acrylate) matrix filled with cellulose nanowhiskers," Cellulose, vol. 19, no. 4, pp. 1225-1237, 2012.

[53] A. I. Raafat, A. A. Saad Eldin, A. A. Salama, and N. S. Ali, "Characterization and bioactivity evaluation of (starch/Nvinylpyrrolidone)-Hydroxyapatite nanocomposite hydrogels for bone tissue regeneration," Journal of Applied Polymer Science, vol. 128, no. 3, pp. 1697-1705, 2012.

[54] A. E. Bird, "Amoxicillin," Analytical Profiles of Drug Substances and Excipients, vol. 23, pp. 1-52, 1994.

[55] Y. Yue, X. Wang, J. Han et al., "Effects of nanocellulose on sodium alginate/polyacrylamide hydrogel: mechanical properties and adsorption-desorption capacities," Carbohydrate Polymers, vol. 206, pp. 289-301, 2019.

[56] D. H. Hanna and G. R. Saad, "Encapsulation of ciprofloxacin within modified xanthan gum- chitosan based hydrogel for drug delivery," Bioorganic Chemistry, vol. 84, pp. 115-124, 2019.

[57] F. Ganji, S. Vasheghani-Farahani, and E. Vasheghani-Farahani, "Theoretical description of hydrogel swelling: a review," Iranian Polymer Journal, vol. 19, no. 5, pp. 375-398, 2010.

[58] D. Soto and H. Oliva, "Métodos para preparar hidrogeles químicos y físicos basados en almidón: una revisión," Revista Latinoamericana de Metalurgia y Materiales, vol. 32, no. 2, pp. 154-174, 2012.

[59] S. S. Bhattacharya, A. K. Ghosh, S. Banerjee, P. Chattopadhyay, and A. Ghosh, "Al3 +ion cross-linked interpenetrating polymeric network microbeads from tailored natural polysaccharides," International Journal of Biological Macromolecules, vol. 51, no. 5, pp. 1173-1184, 2012.

[60] H. K. Singh Yadav and H. G. Shivakumar, "In vitro and in vivo evaluation of $\mathrm{pH}$-sensitive hydrogels of carboxymethyl chitosan for intestinal delivery of theophylline," ISRN Pharmaceutics, vol. 2012, Article ID 763127, 9 pages, 2012.

[61] C. J. Pérez-Martínez, T. Del Castillo-Castro, M. M. CastilloOrtega, D. E. Rodríguez-Félix, P. J. Herrera-Franco, and V. M. Ovando-Medina, "Preparation of polyaniline submicro/ nanostructures using L-glutamic acid: loading and releasing studies of amoxicillin," Synthetic Metals, vol. 184, pp. 41-47, 2013.

[62] D. E. Rodríguez-Félix, M. M. Castillo-Ortega, D. Real-Félix, J. Romero-García, A. S. Ledezma-Pérez, and F. RodríguezFélix, "Synthesis and swelling properties of $\mathrm{pH}$ - and temperature-sensitive interpenetrating polymer networks composed of polyacrylamide and poly( $\gamma$-glutamic acid)," Journal of Applied Polymer Science, vol. 119, no. 6, pp. 3531-3537, 2010.

[63] M. M. Castillo-Ortega, A. Nájera-Luna, D. E. Rodríguez-Félix et al., "Preparation, characterization and release of amoxicillin from cellulose acetate and poly(vinyl pyrrolidone) coaxial electrospun fibrous membranes," Materials Science and Engineering: C, vol. 31, no. 8, pp. 1772-1778, 2011.

[64] Q. Xu, W. Huang, L. Jiang, Z. Lei, X. Li, and H. Deng, "KGM and PMAA based $\mathrm{pH}$-sensitive interpenetrating polymer network hydrogel for controlled drug release," Carbohydrate Polymers, vol. 97, no. 2, pp. 565-570, 2013.

[65] R. A. J. Birudaraj, B. Berner, S. Shen, and X. Li, "Buccal permeation of buspirone: mechanistic studies on transport pathways," Journal of Pharmaceutical Sciences, vol. 94, no. 1, pp. 70-78, 2005.
[66] S. Amuriza, "Administracion de medicamentos en pacientes con nutricion enteral mediante sonda," Nutricion Hospitalaria, vol. 21, no. 4, pp. 1-216, 2006.

[67] R. Sutherland, E. A. P. Croydon, and G. N. Rolinson, "Amoxycillin: a new semi-synthetic penicillin," British Medical Journal, vol. 3, no. 5817, pp. 13-16, 1972.

[68] D. Aycan and N. Alemdar, "Development of $\mathrm{pH}$-responsive chitosan-based hydrogel modified with bone ash for controlled release of amoxicillin," Carbohydrate Polymers, vol. 184, pp. 401-407, 2018.

[69] G. Sánchez-Martinez, U. J. Garza-Ramos, F. L. Reyna-Flores, J. Gaytán-Martínez, I. G. Lorenzo-Bautista, and J. SilvaSanchez, "In169, a new class 1 integron that encoded blaIMP18 in a multidrug-resistant Pseudomonas aeruginosa isolate from Mexico," Archives of Medical Research, vol. 41, no. 4, pp. 235-239, 2010.

[70] A. U. Khan, L. Maryam, and R. Zarrilli, "Structure, genetics and worldwide spread of New Delhi metallo- $\beta$-lactamase (NDM): a threat to public health," BMC Microbiology, vol. 17, no. 1, pp. 1-12, 2017.

[71] R. J. Glisoni, M. J. García-Fernández, M. Pino et al., “ $\beta$-Cyclodextrin hydrogels for the ocular release of antibacterial thiosemicarbazones," Carbohydrate Polymers, vol. 93, no. 2, pp. 449-457, 2013. 